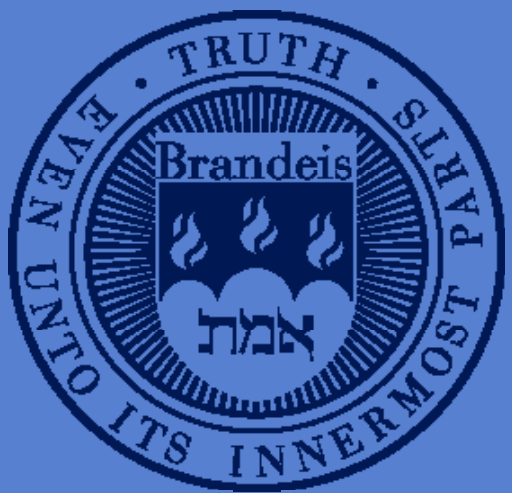

\title{
Immigrant Artists: Enrichment or Displacement?
}

Karol Jan Boroweicki, University of Southern Denmark

Kathryn Graddy, International Business School, Brandeis

University

Working Paper Series 


\title{
Immigrant Artists: Enrichment or Displacement?
}

\author{
Karol Jan Borowiecki ${ }^{1}$ \\ Kathryn Graddy ${ }^{2}$
}

July 21, 2018

${ }^{1}$ University of Southern Denmark, kjb@sam.sdu.dk.

${ }^{2}$ Brandeis International Business School, Brandeis University, and the CEPR, kgraddy@brandeis.edu.

${ }^{3}$ The authors wish to thank Orley Ashenfelter, Kevin O'Rourke, Paul Sharp, Joel Waldfogel, and participants at the Western Economic Association Annual Conference, European Workshop on Applied Cultural Economics, Annual Conference of the Danish Society for Economic and Social History, the 20th International Conference on Cultural Economics, and the Urban, Regional and International Economics Workshop for helpful consultations and insightful comments. 


\begin{abstract}
In order to investigate the role of immigrant artists on the development of artistic clusters in U.S. cities, we use the US Census and American Community Survey, collected every 10 years since 1850 . We identify artists and art teachers, authors, musicians and music teachers, actors and actresses, architects, and journalists, their geographical location and their status as a native or an immigrant. We look at the relative growth rate of the immigrant population in these occupations over a ten year period and how it affects the relative growth rate of native-born individuals in these artistic occupations. We find that cities that experienced immigrant artist inflows also see a greater inflow of native artists.
\end{abstract}


"Everywhere immigrants have enriched and strengthened the fabric of American life." John F. Kennedy

\section{Introduction}

Immigrants have played an outsized role in the development of art and culture in the United States. As indicated by US census reports, in 1880, foreignborn musicians comprised approximately $60 \%$ of all individuals reporting their occupation as musicians or music teachers in the U.S. During and after World War II, New York took over as the center of the modern art world, largely due to European immigration. At the same time, Boston became a center of architectural design, with well-known immigrant architects such as Walter Gropius on the faculty of the Harvard Graduate School of Design. While stories abound, the impact of immigrant artists on these developments has not been established formally. This paper seeks to measure the effect that immigrant artists have had on the growth of artistic occupations in U.S. cities.

The modern view is that the cultural and creative sectors are among the most dynamic sectors in the world economy and are a substantial source of growth, especially in cities. There has been extensive work in the field of economic geography documenting the importance of amenities and culture to the growth of cities. Leading work in this area includes Andersson 
[1985], Quigley [1998], Glaeser et al. [2001], Florida [2014], and Clark et al. [2002]. Throsby [2001] focuses specifically on the interaction of culture and the economy. Recent academic papers have also provided some evidence for this role (for example, Backman and Nilsson [2018], Falck et al. [2018], and Falck et al. [2011]).

In this paper, we thus seek to understand the role of immigrants on the very important artistic sectors, and potentially, the role of immigrant artists on the settlement and growth of cities in the United States. Our prior hypothesis is that like in high technology, as shown by Kerr and Lincoln [2010], immigrant artists "crowd-in" native artists.

In order to study the effect, we use the $1 \%$ sample of the US Census and American Community survey, collected every 10 years since 1850, to identify individuals in the occupations of artists and art teachers, authors, musicians and music teachers, actors and actresses, architects, and journalists, as well as their geographical locations. By using such a long time series, we can explore very long term effects. We use the methodology described in Card and DiNardo [2000], measuring the effect of the relative growth of immigrant artists in the previous 10 year period, on the relative growth of the native artistic population. This approach diminishes the concern of spatial correlation between the levels of immigrant shares and levels of native shares due to common fixed influences. We also present instrumental variable estimates, using immigration to a city and number of clergymen in a city in the previous 
ten year period as instruments. In both our OLS and IV estimates, we find that an increase in the relative growth of the immigrant population of artists increases the relative growth of the native population of artists.

This paper proceeds as follows. In section II we briefly summarize the literature in the arts and labor markets. Section III describes our data and presents summary statistics. In section IV we present our methodology and in section $\mathrm{V}$ we present our results. Section VI interprets our findings and concludes the analysis.

\title{
II Immigration, Labor Markets, and The
}

\begin{abstract}
Arts
In this section we describe the numerous studies that have been undertaken regarding immigration, labor markets, and the arts in order to place our study in context. We start with a description of the most well-known and relevant studies on immigration, proceed to the concept of the artist as an innovator, then look at the arts as an occupation. We end this section with a description of papers on migration patterns and clusters of artists.
\end{abstract}




\section{IIA Immigration}

The role of immigration on native workers has been a topic widely studied by labor economists. While early studies were primarily concerned with the possibility of displacement effects of native low-skilled workers by immigrants (see, for example, Borjas [1987], Card [1990], Card [2001], Card and DiNardo [2000], and Dustmann et al. [2005]), more recent studies have focused on the effects of immigrants on innovation and technology clustering. In recent research in high technology industries (Kerr and Lincoln [2010]), displacement effects have been ruled out, and small crowding-in effects have been documented. Employment and invention increases through the contribution of immigrants.

\section{IIB Artists as Innovators}

Artists have long been considered innovators. In a series of articles, Galenson and Weinberg studied the age at which artists did their best work, as indicated by sale price at subsequent auction. They termed artists who were young when their best work was created as "conceptualists" and artists who were older as "experimentalists." Both innovated, but were different types of innovators. Specifically, in their study of American artists that were born between 1900 and 1940, they termed artists that were born between 1900 and 1920, a large portion of whom are known as abstract expressionists, as experimentalists and those born between 1920 and 1940 as conceptualists 
- who produced their best work at a younger age (Galenson and Weinberg $[2000])$.

\section{IIC Art as an Occupation}

Wassall and Alper [1985] were some of the first economists to use panel data to explore artists and their occupations. They used the National Science Foundation's National Survey of College Graduates (NSCG) to determine whether or not artists were more likely than individuals in other occupations to change jobs. Smith [2000] used the 1970 Census to determine the propensity for individuals to move in and out of artistic occupations. Alper and Wassall [2006] went on to study employment and earnings of American artists using decennial US Census data from 1940 to 2000.

\section{IID Migration and Clustering of Artists}

O'Hagan and Borowiecki [2010], Borowiecki and O'Hagan [2012], and Borowiecki [2013] have studied migration patterns of music composers and geographic clustering. New York is a major work location for composers; the fifth most important city for composers born in the 19th century, and the second most popular destination for 20th century composers, after Paris. They find that composers have remarkable mobility. $27 \%$ of the top composers have moved permanently abroad during their life, while $59 \%$ migrated internally since the 12th century. O'Hagan and Hellmanzik [2008] found that the predominant 
location for visual artists born in the first half of the 20th century is New York City, with most prominent American artists clustering there. Kelly and O'Hagan [2007] found a strong propensity for artists to cluster, and Hellmanzik [2010] found that there is price premium for artists that cluster in New York or Paris, and artists in these clusters produce their work at an earlier age.

This clustering includes both immigrant and native artists. This paper asks whether clustering by immigrant artists increases or decreases the number of natives in artistic occupations.

\section{The Data}

The primary dataset we use for our analysis is the $1 \%$ sample of the US Census and American Community Survey, provided by the Integrated Public Use Microdata Series - USA (IPUMS-USA). Borowiecki [2017] provides a good statistical description of this datset. This comprehensive decennial population census provides a large array of variables, collected every 10 years, and since 1850 includes also information on the occupational status of individuals (OCC1950). This variable is used in order to identify the following occupations for household heads: artists and art teachers, authors, musicians and music teachers, actors and actresses, architects, and journalists, including editors and reporters. The Census data also contain information 
on the geographical locations of the individual artist as well as their place of birth. We use country of birth to identify immigrants versus native-born Americans.

Figure I demonstrates the growth and importance of artistic employment during the late nineteenth and twentieth centuries. In terms of total employment, artistic employment is nontrivial, increasing to about $0.1 \%$ of all occupations by the end of the 20th century. The share of musicians and music teachers is especially high and takes off during the late 20th century reaching $0.7 \%$, with the other occupations showing stable or more modest growth.

Figure II shows the importance of immigrants to these occupations. As is evident, a very high share of individuals in artistic occupations have immigrated from abroad. While the North American population consists in general of a high share of foreign-born individuals, the share of immigrants reached $60 \%$ of musicians in 1880 . By the 1960 s, the share of immigrants in artistic occupations converges to the average for all household-heads.

For our analysis, we break down populations by cities. During this period, the relative population, and even existence of cities, changed tremendously. To demonstrate this change and to present the variables that we will be using in the paper, Table I provides summary statistics on the variables by breaking up the period into pre- and post-1920. As would be expected, population growth of both immigrants and natives was greater pre-1920 than 
post-1920. Furthermore, the relative growth of the artistic population was greater earlier than later. While the proportion of immigrants was greater pre-1920, the average number of teachers and clergymen was greater post1920 (both variables have been obtained from the occupation record in the Census).

We focus on household heads as they were typically the decision makers, and hence also took the decisions about location. The result is that this anlysis is primarily about male artists, reflecting cultural norms of the period under investigation.

\section{Methodology}

A common challenge in estimating the effects of local labor market variation in immigrant populations on the native population is the problem of spatial correlation. This would not be the case if immigrants were randomly allocated across local labor markets. However, it is likely that levels of immigrant shares and levels of native shares may be spatially correlated because of common fixed influences, leading to a positive or negative statistical correlation between immigrant and native concentrations, even in the absence of any genuine effects of immigration. Elimination of common fixed influences could be achieved by using changes in native concentrations and relating them to changes in immigrant concentrations. This is the approach used in 
Card and DiNardo [2000] and the aproach we initially pursue below.

The primary variable that we focus on is proportion of artists in a city, $P_{a c}$, relative to the total population in a city $P_{c} \cdot{ }^{1}$. We decompose changes in this proportion into changes that are driven by the immigrant population (M) and changes that are driven by the native population $(\mathrm{N})$, so that $P_{c}=$ $M_{c}+N_{c}$. The natural log of the change in the proportion of artists to the total population is then approximately

$$
\Delta \ln P_{a c} / P_{c}=\left(\Delta M_{a c} / P_{a c}-\Delta M_{c} / P_{c}\right)+\left(\Delta N_{a c} / P_{a c}-\Delta N_{c} / P_{c}\right)
$$

The first term is the relative growth rate of immigrants in the artist population and the second is the relative growth rate of natives in the artist population. So, the total growth rate of artists relative to the entire population is that sum of these two parts.

As is usual, we then propose that natives react as follows to immigrant inflow:

$$
\left(\Delta N_{a c} / P_{a c}-\Delta N_{c} / P_{c}\right)=a+b\left(\Delta M_{a c} / P_{a c}-\Delta M_{c} / P_{c}\right)+\eta_{a c}
$$

where $\eta_{a c}$ is an error term.

By substitution, the overall change in the log population share of artists

\footnotetext{
${ }^{1}$ Agglomeration research typically identifies cities as the relevant spatial unit to study labor market effects, for example, Rosenthal and Strange [2001] and Ellison et al. [2010]
} 
can be written as:

$$
\Delta \ln P_{a c} / P_{c}=a+(1+b)\left(\Delta M_{a c} / P_{a c}-\Delta M_{c} / P_{c}\right)+\eta_{a c}
$$

If $b<0$ then native outflows occur if there are immigrant inflows, and if $b=-1$, then native outflows exactly offset immigrant inflows. If $\mathrm{b}=0$, then population changes of natives are not affected by the relative inflow rate of immigrants. If $\mathrm{b}>0$, then native inflows increase with immigrant inflows. Hence, we can test for the effect of immigrant inflows on the native artist occupation.

When estimating equation 3, we plan to first use plausibly exogenous covariates to account for the possibility that a simple first-differenced specification may not sufficiently capture the dynamics of population change. (As noted before, using relative growth rates may partially mitigate other possible influences.) Specifically, we include the relative growth of the native artistic population over a preceding period (i.e., the lagged dependent variable) and the lagged proportion of immigrants. We then also include measures of city population growth and lagged city population growth.

One concern with the above specification is that demand shocks that are specific to cities and artists can deter or attract both native and immigrant artists from a particular city. This selective settlement would lead to a downward biased estimate. An additional problem in the calculation of immigrant 
concentrations at the city level is measurement error. This is likely to be the case in a study that is based on a survey of relatively small sample size, or when using differenced and within groups estimation.

A possible solution to the problems above is to use measures of historic settlement patterns as an instrument for the relative growth rate of the immigrant artistic population. Given the long time series of the chosen census, we are able to measure historic settlement patterns with the previous 10-year proportionate change in immigrant population. ${ }^{2}$ The underlying identification assumption is that immigrants in artistic occupations will be attracted to areas that see increases in the number of individuals with the same cultural and linguistic background as themselves, inducing immigrants in artistic occupations to settle in areas with fast growing immigrant populations.

We propose also a second instrumental variable, inspired by "The Brain of the Nation." In his article, Michaud [1905] sets out to depict the geographic spread of intellectual and artistic talent in the American states in 1900 and provides efforts to identify "the laws which obtain in the distribution of intellectuality." Based on samples of contemporaneous famous people of literary, artistic, or scientific backgrounds, Michaud arrives at the conclusion that immigrants may be roughly divided into two categories: those who "wished to improve their position through the acquisition of property, and those who wished above all to enjoy religious freedom." While the first

\footnotetext{
${ }^{2}$ We are grateful to Joel Waldfogel for this helpful suggestion.
} 
category of immigrants - those motivated by economic factors - are the populations typically modeled in labor economics, the second category - those pulled by religious liberty - are often ignored. As such, the underlying paper provides novel insights on and the first test of Michaud's hypothesis.

We approximate religious freedom with clergymen, specifically the lagged number of clergymen, obtained from the occupation variable in the Census. The assumptions necessary for identification with this instrument are similar to our above assumptions; the lagged number of clergymen is correlated with the relative growth rate of immigrant artists, but only influences the relative growth rate of natives in artistic occupations through artistic immigrants. ${ }^{3}$

\section{Estimation}

We estimate equation 3 in several ways. In the first part of this section we present OLS estimates using a pooled sample and controlling for occupation, and then estimating each artistic occupation separately. In the second part of the section, we present our instrumental variable regressions.

\footnotetext{
${ }^{3}$ During the covered time period in the United States executing art was not forbidden nor encouraged by organized religion as it may have been the case during the hegemony of the Church during the Middle Ages.
} 


\section{VA Ordinary Least Squares Estimation}

Using a pooled sample of all artist occupations and then controlling for oc-

cupation, we present the results in Table II. Our variable of interest is the relative growth of the immigrant population in each of the artistic occupations and how that effects the relative growth of the native population in each of the artistic occupations. We construct this variable by census city, taking the relative change (relative to the total city population) in each of the artistic populations over a 10 year period. As shown in Table II, although we begin with over 35,000 city-periods, this quickly drops when we look at the number of individuals in each artistic occupation in each city in this $1 \%$ sample, as many city-10-year time periods have no individuals in these artistic occupations. When we difference for growth rates, we are left with 4,298 observations. In column 1, without using any controls we find that on average, the relative growth of the immigrant population in artistic occupations does not effect the relative growth of the native population in the artistic occupations.

In column 2, we add two lags: the relative growth rate of the native artistic population in the previous 10 year period, and the lagged proportion of immigrants in the previous 10 year period. When the lagged variables are added, the relative growth of immigrant artists positively effects the relative growth of native artists. The magnitude of the OLS results indicate that for each $10 \%$ increase in the immigrant population we would have about a $5 \%$ 
increase in the native population. This effect persists and increases to $7 \%$ when we add year fixed effects and state fixed effects (column 3), or extend further by the change in the total city population and the lagged change in the total city population (column 4).

When broken out by artist occupation, our regression results from the estimation of equation 3 look as in Table III. None of the individual coefficients on the relative growth of the immigrant artistic population for each occupation differ significantly from the average estimates. Furthermore, the coefficients for the artists and musicians sample are positive and significant at the $1 \%$ level, the coefficients on the architect sample are positive and significant at the $5 \%$ level, and on author and journalist, the coefficients are positive and significant at the $10 \%$ level. The only insignificant coefficient is found in the actors regression in which there are only 53 observations. Immigration by people in artistic occupations does not crowd out, but rather crowds in, native artists.

\section{$V B$ Instrumental Variables Estimation}

Table IV presents our Instrumental Variable results, using the proportionate change in the immigrant population in the past 10 years, as a measure of historical settlement patterns, and using the lagged number of clergymen, as a proxy for religious freedom. As would be expected, all specifications indicate that immigration in artistic occupations is positively and significantly 
related to overall immigration, though the coefficient of interest is imprecisely estimated when just the clergy measure is used as an instrument. In column 6, when using both instruments, we continue to find a strong positive and statistically significant impact of the relative growth of immigrant artists on the relative growth of native artists. The magnitude of the IV-coefficient in this specification indicates that for each $10 \%$ increase in the immigrant population we would have about an $8 \%$ increase in the native population.

\section{VC The channel: Internal migrants or new artists?}

The observed positive and enforcing relationship between migrant and native populations of artists is interesting, but raises the question whether the native population increase is due to internal migration (for example, U.S. born artists moving from the midwest to New York) or rather as a result of uptake of artistic jobs by locals. For this reason we re-estimate the models for relative growth rates of artistic natives who were born in another place (i.e., internal migrants) and artistic natives born in the same place (i.e., stayers). The results are presented in Table $\mathrm{V}$.

The estimation indicates that both the relative growth rate of internal migrants (columns 3-4) and stayers (columns 5-6) increase with higher relative growth rates of immigrants (columns 1-2 show the baseline model, which is the sum of migrants' and stayers' estimated rates). The association

is stronger for internal migrants, which may reflect the fact that migration 
streams, whether from abroad or internally, follow a similar direction. The point estimates with stayers is nonetheless meaningful and highly significant: a $10 \%$ higher relative growth rate of the immigrant population increases the relative growth rate of locals in arts by up to $3.4 \%$. This is an important result that signifies the complementarity between foreign migrants and native stayers, and supports the hypothesized role that immigrants have played on the development of local arts clusters.

\section{VD Robustness tests}

A number of concerns can be raised in relation to the previous estimates. First, the number of teachers in artistic occupations increased rapidly after 1920, and an important question is whether it is the number of teachers or the proportion of teachers in the overall population that is driving the estimates. As Table VI shows, while the teacher population does have in both specifications a positive effect on the relative growth of the native artistic population, our results are not significantly different when controlling for teachers.

A second concern is that artists may be attracted to areas that are more racially and ethnically diverse, or simply large cities. The significance of racial or ethnic diversity could have an impact on the integrity of our instrument - the proportionate change in the immigrant population. Perhaps artists are attracted to areas directly because of the number of immigrants, 
which also results in racial or ethnic diversity. Therefore, we introduce an additional control for ethnic diversity, which is calculated as the probability that two individuals taken at random from our sample represent a different race. We also introduce an analogous measure for country of birth diversity. ${ }^{4}$ In order to account for the role of large cities, we introduce a control variable measuring the city size or drop the largest cities. As Table VII shows, racial diversity and city size are positively related with the relative growth of native artistic population, albeit the former variable is significant only at the $10 \%$ level (columns 1 and 2). However, these additional controls have no effect on our baseline estimates, which are also robust to the dropping of particularly large cities (columns 3 and 4).

\footnotetext{
${ }^{4}$ More formally, our diversity measure constitutes the standard Gini-Simpson index, which is equal to $\sum_{n=i} p_{i}^{2}$, where $p_{i}$ represents the proportion of each race. Our country of birth diversity index is calculated in analogy, but considers country of birth instead of race.
} 


\section{Discussion and Conclusion}

This paper seeks to measure the effect that immigrant artists have had on the growth of artistic occupations in U.S. cities. The historical data allows us to look for very long term effects. We find that immigrants have played an outsized role in the development of art and culture in the United States, by crowding in, rather than crowding out, native artists. The results indicate that cities which experienced an inflow of migrant artists, see also an inflow of native artists.

These results could be due to several factors. First, with more migrant artists a city may become more vibrant and diverse, increasing its attractiveness and stimulating knowledge spillovers (Glaeser et al. [1992]). Second, the findings could be related to economies of scale: with a greater supply of artistic output, the average price per unit of output decreases. For example, with more musicians there can be staged more concerts in the local concert hall, which leads to a drop in price of an average concert. These effects are nonnegligible due to the typically very high fixed costs of cultural infrastructure. Third, at play could be also economies of scope, leading to lower production

costs if a higher variety of goods are produced. Staying with the example of the concert hall: the venue can be used for other artistic ventures, such as performing arts (involving actors) or to stage opera (musicians).

All in all, the results provide new insights on the complementary role 
of migrants, who have likely stimulated the development of local arts and cultural scenes, which have with time developed to international, important art clusters. The findings in the paper support thus the view that immigrants have indeed enriched and strengthened the development of the United States. 
Figure I: Share of Creatives by Creative Occupation

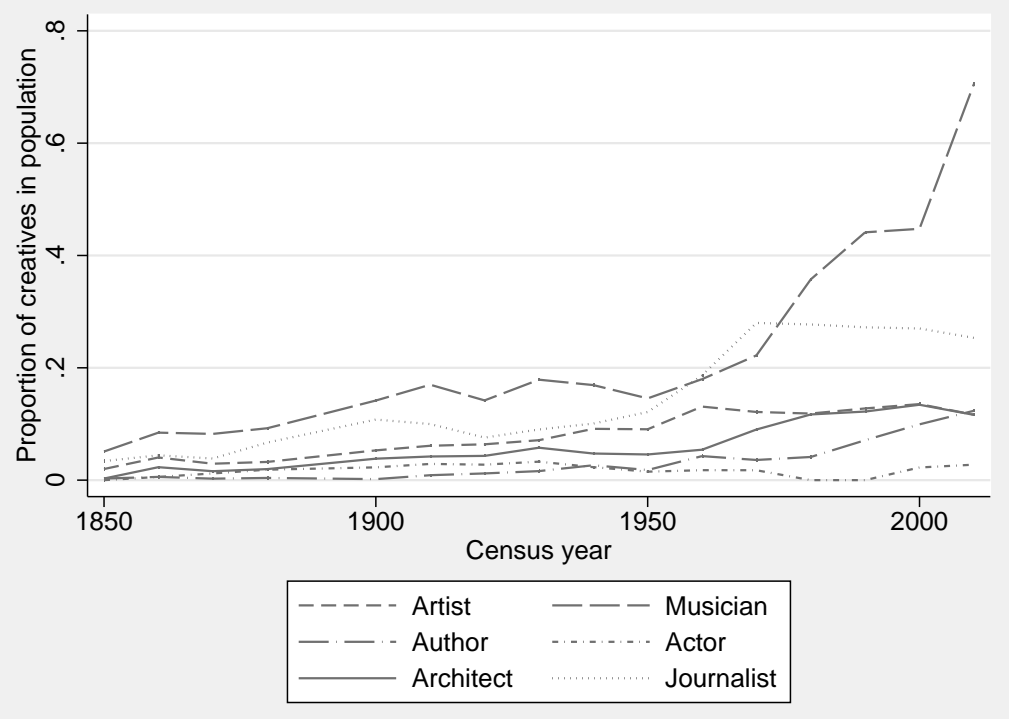

Figure II: Share of Immigrants by Creative Occupation

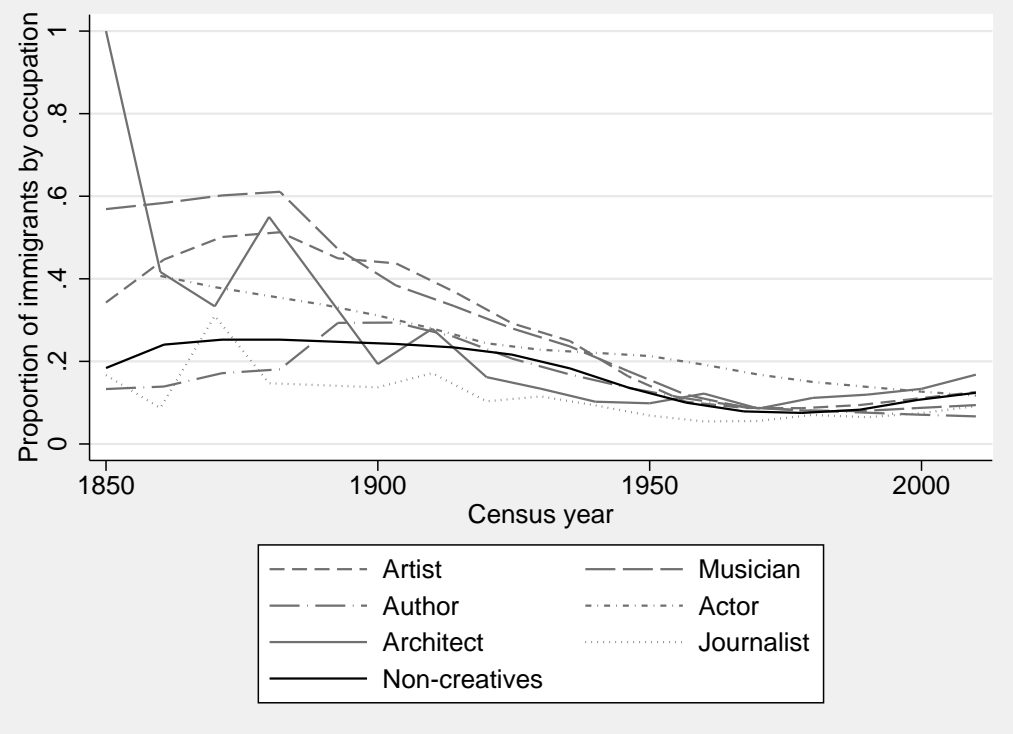


Table I: Summary Statistics

\begin{tabular}{lccc}
\hline & $(1)$ & $(2)$ & $(3)$ \\
& pre-1920 & post-1920 & Overall \\
\hline \multicolumn{4}{c}{ Percentage growth } \\
\hline A. Total population growth & 0.110 & 0.027 & 0.035 \\
Immigrants & $(0.171)$ & $(0.060)$ & $(0.082)$ \\
& 0.199 & 0.141 & 0.147 \\
Natives & $(0.152)$ & $(0.228)$ & $(0.222)$ \\
& 0.309 & 0.168 & 0.182 \\
Total & $(0.244)$ & $(0.252)$ & $(0.255)$ \\
& & & \\
B. Relative growth of artistic population & \multicolumn{3}{c}{} \\
Immigrants & 0.141 & -0.012 & 0.003 \\
& $(0.484)$ & $(0.333)$ & $(0.354)$ \\
Natives & 0.291 & 0.026 & 0.052 \\
& $(0.609)$ & $(1.238)$ & $(1.192)$ \\
Total & 0.432 & 0.013 & 0.055 \\
& $(0.543)$ & $(1.298)$ & $(1.250)$ \\
& \multicolumn{3}{c}{} \\
\hline C. Control and instrumental variables & \multicolumn{3}{c}{} \\
Proportion of immigrants & 0.336 & 0.098 & 0.123 \\
City population growth & $(0.432)$ & $(0.225)$ & $(0.265)$ \\
& 0.499 & 0.388 & 0.423 \\
D.log(Immigrant population) & $(0.672)$ & $(0.670)$ & $(0.672)$ \\
Clergymen (in thousands) & 0.070 & 0.108 & 0.075 \\
& $(1.035)$ & $(1.744)$ & $(1.489)$ \\
Teachers (in thousands) & 0.057 & 0.368 & 0.258 \\
Proportion of teachers & $(0.164)$ & $(0.795)$ & $(0.663)$ \\
in overall population & 0.048 & 2.797 & 1.821 \\
\hline \hline & $(0.179)$ & $(8.742)$ & $(7.144)$ \\
& 0.0040 & 0.0151 & 0.0112 \\
& $(0.0102)$ & $(0.0136)$ & $(0.0135)$ \\
\hline
\end{tabular}

Note: Standard deviations in parentheses. 
Table II: Relative Growth of the Native and Immigrant Artistic Population $\begin{array}{llll}(1) & (2) & (3) & (4)\end{array}$ Relative growth of native artistic population

\begin{tabular}{lcccc}
\hline & \multicolumn{4}{c}{ OLS } \\
\hline Relative growth of & 0.0513 & $0.553^{* * *}$ & $0.681^{* * *}$ & $0.681^{* * *}$ \\
immigrant artistic population & $(0.0513)$ & $(0.0942)$ & $(0.0986)$ & $(0.0985)$ \\
& & & & \\
Lagged relative growth of & & $-0.185^{* * *}$ & $-0.186^{* * *}$ & $-0.184^{* * *}$ \\
native artistic population & & $(0.0285)$ & $(0.0288)$ & $(0.0287)$ \\
Lagged proportion of & & $1.058^{* * *}$ & $1.324^{* * *}$ & $1.309^{* * *}$ \\
immigrants & & $(0.150)$ & $(0.176)$ & $(0.176)$ \\
City population & & & & 0.101 \\
growth & & & & $(0.0806)$ \\
Lagged city & & & & $-0.147^{* * *}$ \\
population growth & $0.177^{* * *}$ & $-0.220^{* *}$ & -0.138 & $0.0563)$ \\
Constant & $(0.0560)$ & $(0.0954)$ & $(1.397)$ & $(1.400)$ \\
& & & & \\
Observations & 4,298 & 1,980 & 1,975 & 1,975 \\
R-squared & 0.007 & 0.064 & 0.094 & 0.099 \\
Occupation controls & $\checkmark$ & $\checkmark$ & $\checkmark$ & $\checkmark$ \\
Year controls & & & $\checkmark$ & $\checkmark$ \\
State controls & & & $\checkmark$ & $\checkmark$ \\
\hline
\end{tabular}

Standard errors in parentheses

*** $\mathrm{p}<0.01,{ }^{* *} \mathrm{p}<0.05,{ }^{*} \mathrm{p}<0.1$ 


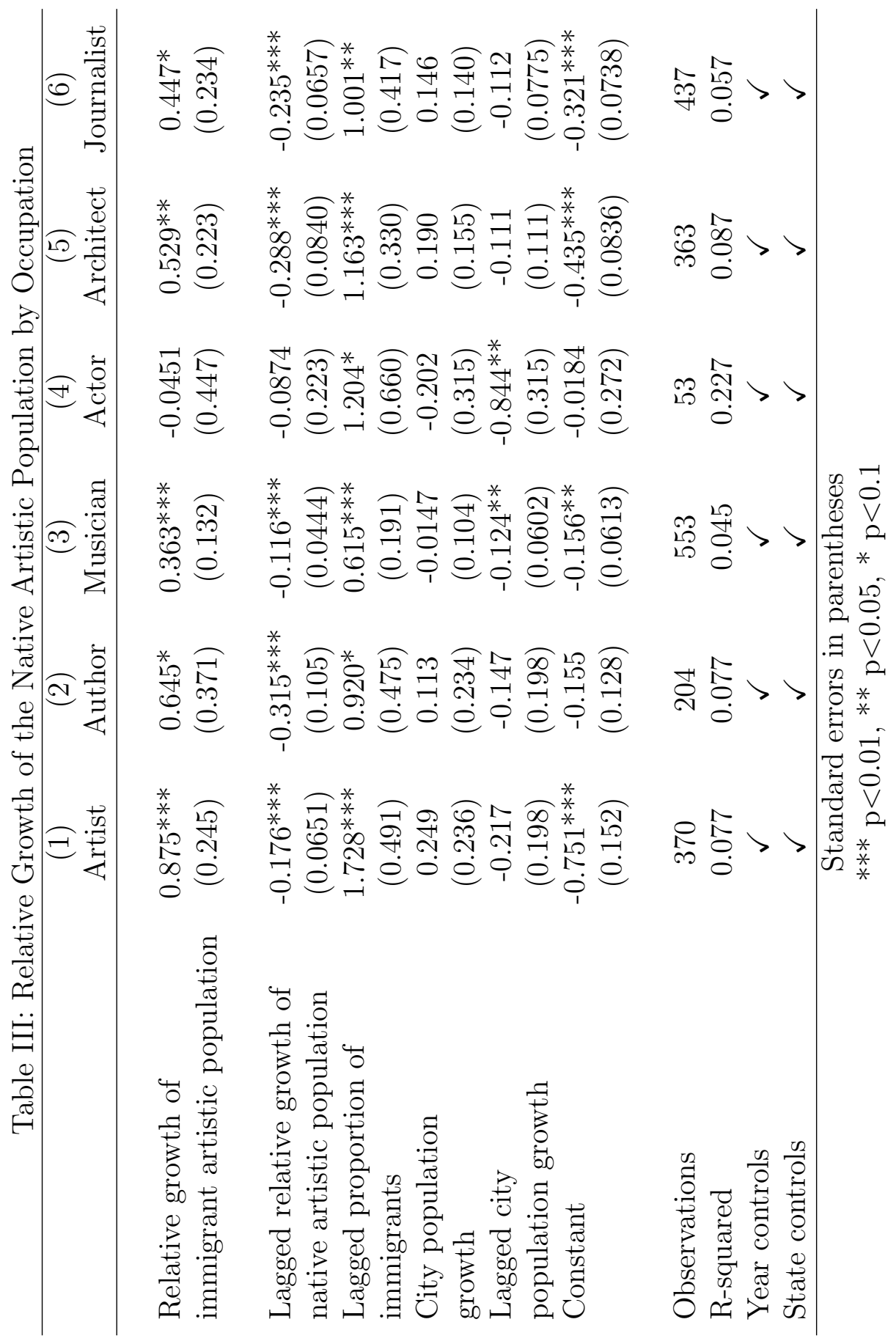




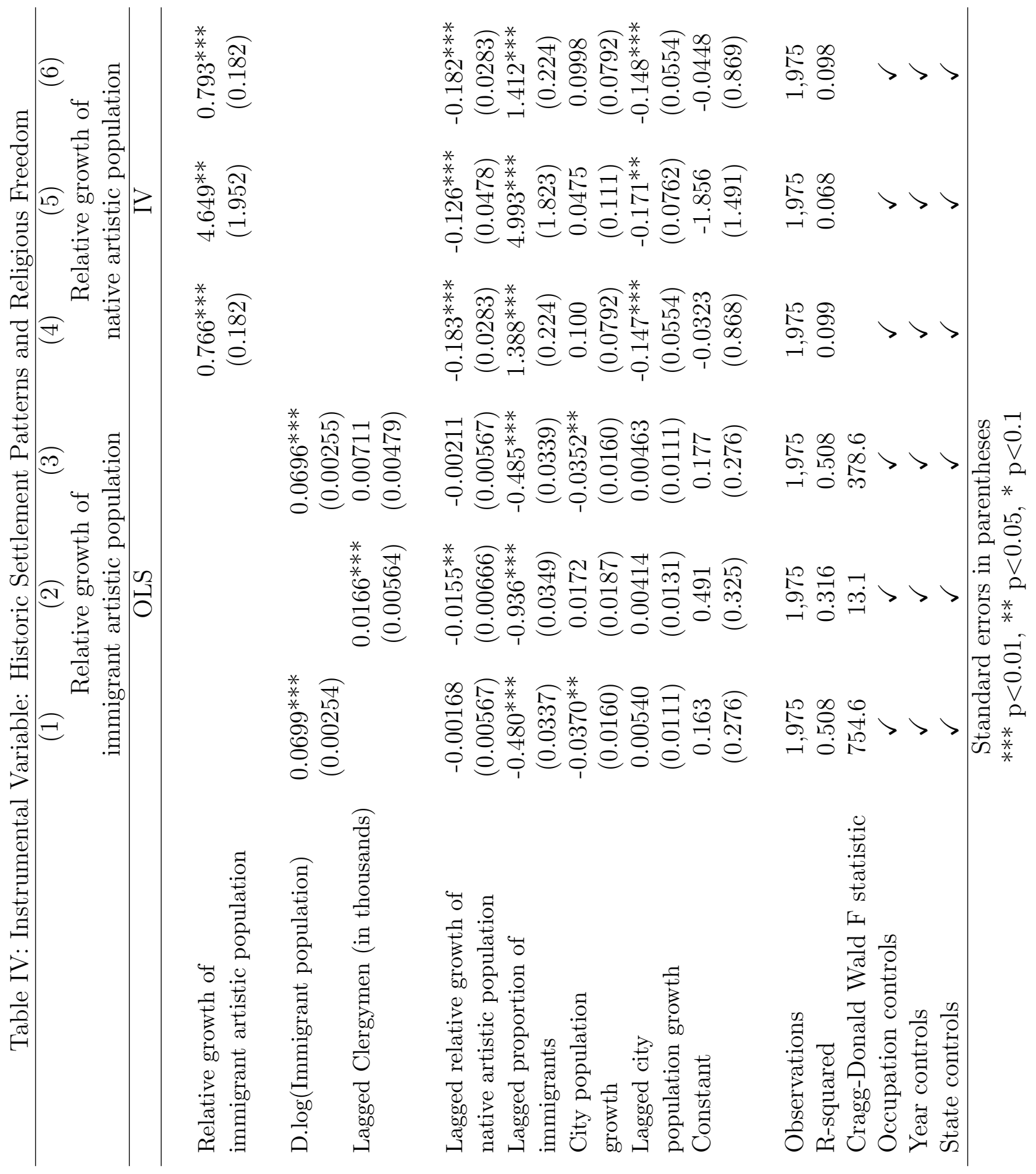




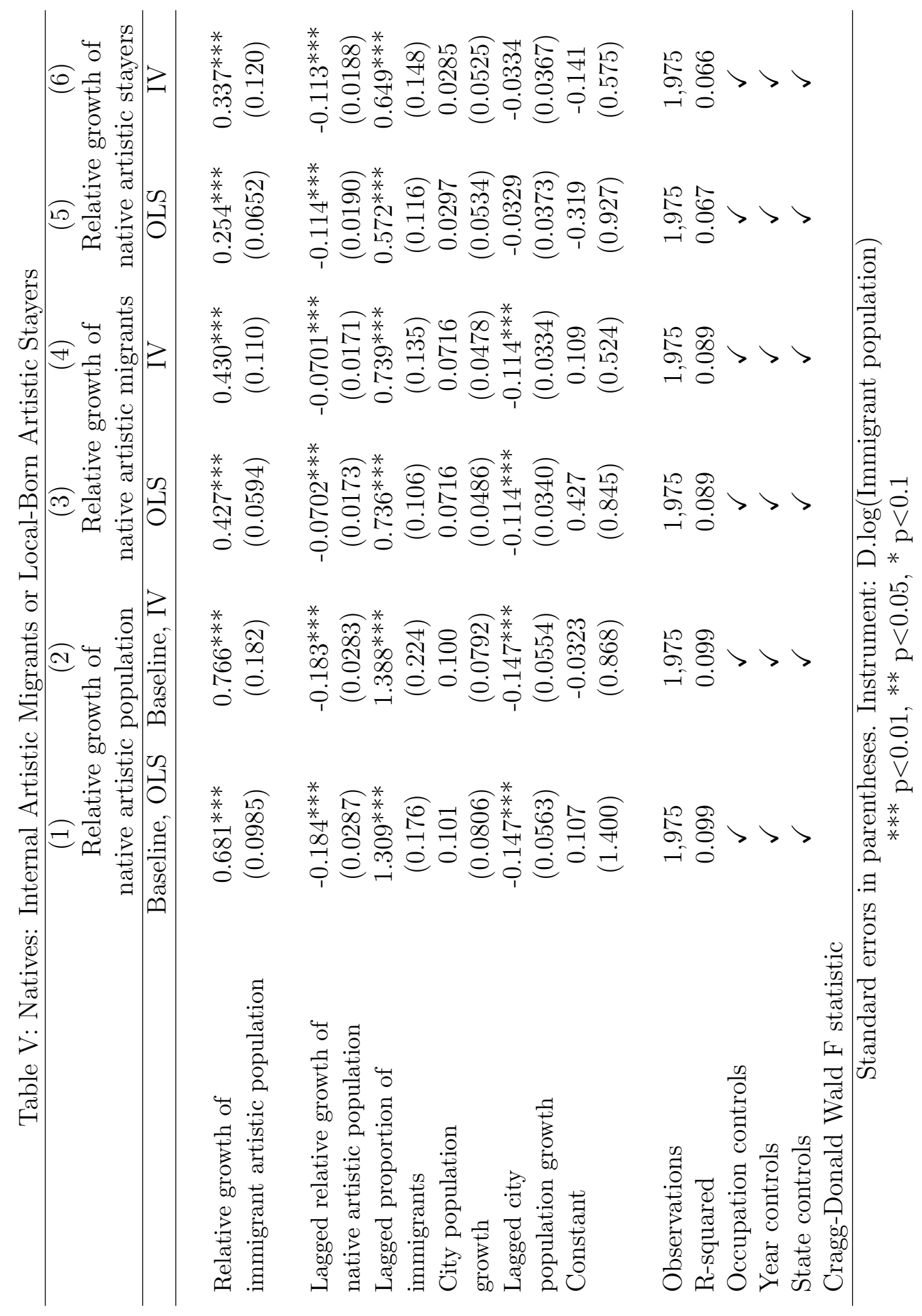


Table VI: Robustness Tests: Controlling for Teachers

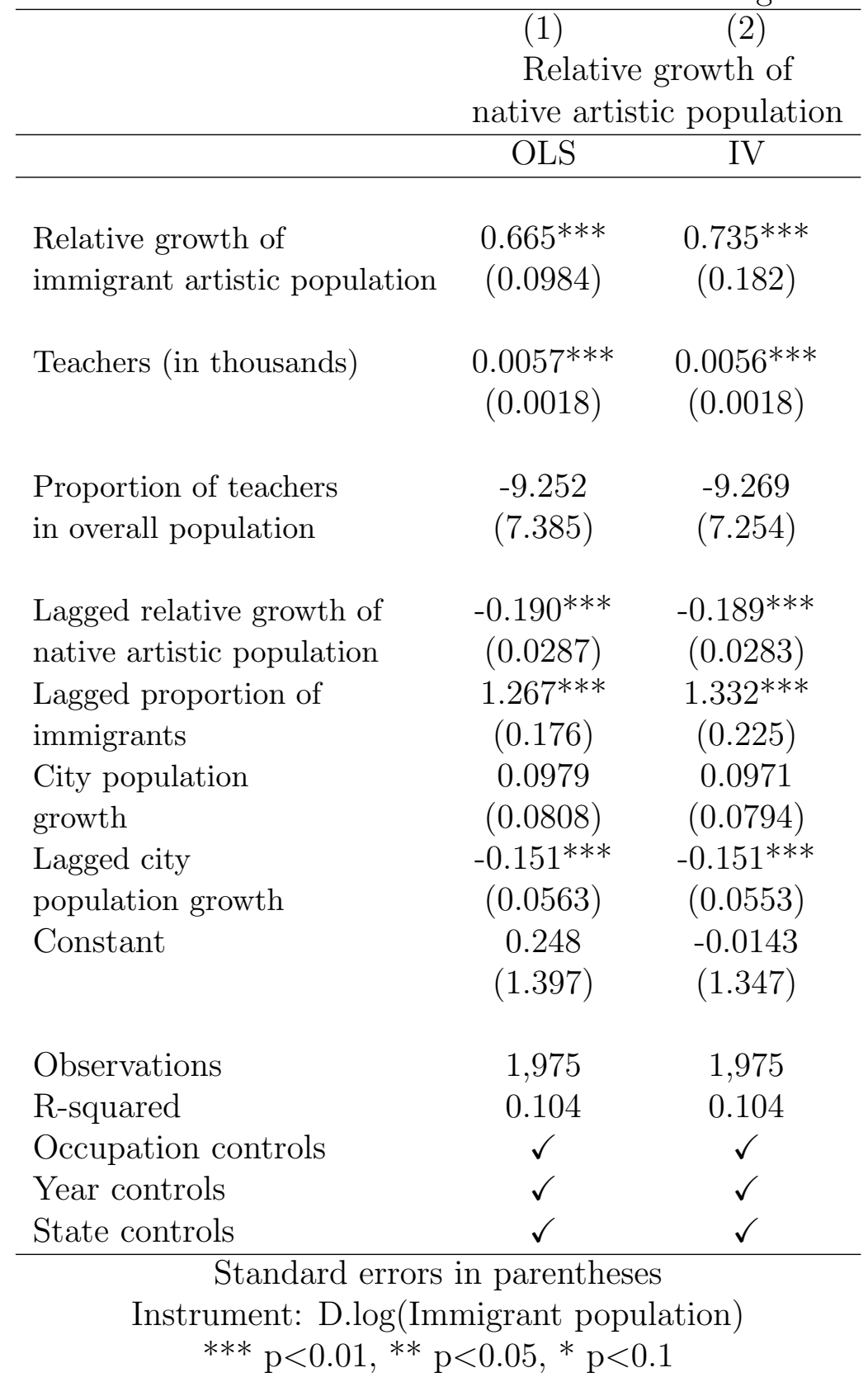


Table VII: Robustness Tests: Racial Diversity, Country of Birth Diversity and City Size

(1) (2) (3) (4)

Relative growth of native artistic population

\begin{tabular}{|c|c|c|c|c|}
\hline & \multicolumn{2}{|c|}{ Whole sample } & \multicolumn{2}{|c|}{$\begin{array}{l}\text { Dropped: New York, } \\
\text { Los Angeles \& Chicago }\end{array}$} \\
\hline & OLS & IV & OLS & IV \\
\hline $\begin{array}{l}\text { Relative growth of } \\
\text { immigrant artistic population }\end{array}$ & $\begin{array}{l}0.671^{* * *} \\
(0.0989)\end{array}$ & $\begin{array}{c}0.736^{* * *} \\
(0.185)\end{array}$ & $\begin{array}{c}0.680^{* * *} \\
(0.103)\end{array}$ & $\begin{array}{c}0.769^{* * *} \\
(0.192)\end{array}$ \\
\hline Racial diversity & $\begin{array}{l}0.691^{*} \\
(0.404)\end{array}$ & $\begin{array}{l}0.706^{*} \\
(0.399)\end{array}$ & & \\
\hline Country of birth diversity & $\begin{array}{r}-0.0996 \\
(0.336)\end{array}$ & $\begin{array}{l}-0.119 \\
(0.333)\end{array}$ & & \\
\hline City size (in millions) & $\begin{array}{l}0.0115^{* *} \\
(0.00583)\end{array}$ & $\begin{array}{l}0.0113^{* *} \\
(0.00574)\end{array}$ & & \\
\hline $\begin{array}{l}\text { Lagged relative growth of } \\
\text { native artistic population }\end{array}$ & $\begin{array}{c}-0.190 * * * \\
(0.0287)\end{array}$ & $\begin{array}{c}-0.189 * * * \\
(0.0283)\end{array}$ & $\begin{array}{c}-0.189^{* * *} \\
(0.0298)\end{array}$ & $\begin{array}{c}-0.187^{* * * *} \\
(0.0294)\end{array}$ \\
\hline $\begin{array}{l}\text { Lagged proportion of } \\
\text { immigrants }\end{array}$ & $\begin{array}{c}1.269^{* * *} \\
(0.180)\end{array}$ & $\begin{array}{c}1.332^{* * *} \\
(0.233)\end{array}$ & $\begin{array}{c}1.322^{* * *} \\
(0.187)\end{array}$ & $\begin{array}{c}1.407^{* * *} \\
(0.240)\end{array}$ \\
\hline $\begin{array}{l}\text { City population } \\
\text { growth }\end{array}$ & $\begin{array}{c}0.113 \\
(0.0823)\end{array}$ & $\begin{array}{c}0.112 \\
(0.0809)\end{array}$ & $\begin{array}{c}0.100 \\
(0.0847)\end{array}$ & $\begin{array}{c}0.0984 \\
(0.0832)\end{array}$ \\
\hline $\begin{array}{l}\text { Lagged city } \\
\text { population growth }\end{array}$ & $\begin{array}{l}-0.139 * * \\
(0.0567)\end{array}$ & $\begin{array}{l}-0.139^{* *} \\
(0.0557)\end{array}$ & $\begin{array}{l}-0.149 * * \\
(0.0606)\end{array}$ & $\begin{array}{l}-0.150^{* *} \\
(0.0595)\end{array}$ \\
\hline Constant & $\begin{array}{c}0.297 \\
(1.409)\end{array}$ & $\begin{array}{l}0.0233 \\
(1.355)\end{array}$ & $\begin{array}{l}-0.104 \\
(1.510)\end{array}$ & $\begin{array}{l}0.0384 \\
(1.019)\end{array}$ \\
\hline Observations & 1,975 & 1,975 & 1,851 & 1,851 \\
\hline R-squared & 0.105 & 0.105 & 0.100 & 0.099 \\
\hline Occupation controls & $\checkmark$ & $\checkmark$ & $\checkmark$ & $\checkmark$ \\
\hline Year controls & $\checkmark$ & $\checkmark$ & $\checkmark$ & $\checkmark$ \\
\hline State controls & $\checkmark$ & $\checkmark$ & $\checkmark$ & $\checkmark$ \\
\hline
\end{tabular}

Standard errors in parentheses. Instrument: D.log(Immigrant population) $* * * \mathrm{p}<0.01,{ }^{*} * \mathrm{p}<0.05,{ }^{*} \mathrm{p}<0.1$ 
Neil Alper and Gregory Wassall. Artists' careers and their labor markets. Handbook of the Economics of Art and Culture, 1:813-864, 2006.

Åke Andersson. Creativity and regional development. In Papers of the Regional Science Association, volume 56, pages 5-20. Springer, 1985.

Mikaela Backman and Pia Nilsson. The role of cultural heritage in attracting skilled individuals. Journal of Cultural Economics, 42(1):111-138, Feb 2018.

George J. Borjas. Immigrants, minorities, and labor market competition. Industrial \& Labor Relations Review, 40(3):382-392, 1987.

Karol Jan Borowiecki. Geographic clustering and productivity: An instrumental variable approach for classical composers. Journal of Urban Economics, 73(1):94-110, 2013.

Karol Jan Borowiecki. The origins of creativity: The case of the arts in the united states since 1850. 2017.

Karol Jan Borowiecki and John W. O'Hagan. Historical patterns based on automatically extracted data: the case of classical composers. Historical Social Research (Section 'Cliometrics'), 37(2):298-314, 2012.

David Card. The impact of the mariel boatlift on the miami labor market. Industrial \&6 Labor Relations Review, 43(2):245-257, 1990.

David Card. Immigrant inflows, native outflows, and the local labor market 
impacts of higher immigration. Journal of Labor Economics, 19(1):22-64, 2001.

David Card and John DiNardo. Do immigrant inflowsl lead to native outflows? American Economic Review, 90(2):360-367, May 2000.

Terry Nichols Clark, Richard Lloyd, Kenneth K. Wong, and Pushpam Jain. Amenities drive urban growth. Journal of Urban Affairs, 24(5):493-515, 2002.

Christian Dustmann, Francesca Fabbri, and Ian Preston. The impact of immigration on the British labour market. Economic Journal, 115(507): 324-341, November 2005.

Glenn Ellison, Edward L. Glaeser, and William R. Kerr. What causes industry agglomeration? evidence from coagglomeration patterns. American Economic Review, 100(3):1195-1213, June 2010.

Oliver Falck, Michael Fritsch, and Stephan Heblich. The phantom of the opera: Cultural amenities, human capital, and regional economic growth. Labour Economics, 18(6):755-766, 2011.

Oliver Falck, Michael Fritsch, Stephan Heblich, and Anne Otto. Music in the air: estimating the social return to cultural amenities. Journal of Cultural Economics, Jan 2018.

Richard Florida. The rise of the creative class-revisited: Revised and expanded. Basic Books (AZ), 2014. 
David W. Galenson and Bruce A. Weinberg. Age and the quality of work: The case of modern american painters. Journal of Political Economy, 108 (4):761-777, 2000 .

Edward L. Glaeser, Hedi D Kallal, Jose A. Scheinkman, and Andrei Shleifer. Growth in cities. Journal of Political Economy, 100(6):1126-52, 1992.

Edward L. Glaeser, Jed Kolko, and Albert Saiz. Consumer city. Journal of Economic Geography, 1(1):27-50, 2001.

Christiane Hellmanzik. Location matters: Estimating cluster premiums for prominent modern artists. European Economic Review, 54(2):199-218, 2010.

Elish Kelly and John O'Hagan. Geographic clustering of economic activity: The case of prominent western visual artists. Journal of Cultural Economics, 31(2):109-128, 2007.

William R. Kerr and William F. Lincoln. The supply side of innovation: $\mathrm{H}-1 \mathrm{~b}$ visa reforms and us ethnic invention. Journal of Labor Economics, 28(3):473-508, 2010.

Gustave Michaud. The Brain of the Nation. The Century Magazine, 69: 41-46, 1905.

John O’Hagan and Karol Jan Borowiecki. Birth location, migration, and clustering of important composers. Historical Methods: A Journal of Quantitative and Interdisciplinary History, 43(2):81-90, 2010. 
John O'Hagan and Christiane Hellmanzik. Clustering and migration of important visual artists: broad historical evidence. Historical Methods: A Journal of Quantitative and Interdisciplinary History, 41(3):121-136, 2008.

John M. Quigley. Urban diversity and economic growth. Journal of Economic Perspectives, 12(2):127-138, 1998.

Stuart S Rosenthal and William C Strange. The determinants of agglomeration. Journal of Urban Economics, 50(2):191-229, 2001.

Thomas Smith. Longitudinal analysis of the earnings of artists. 2000.

David Throsby. Economics and Culture. Cambridge university press, 2001.

Gregory Wassall and Neil Alper. Occupational characteristics of artists: A statistical analysis. Journal of Cultural Economics, 9(1):13-34, 1985. 